This item was submitted to Loughborough's Research Repository by the author.

Items in Figshare are protected by copyright, with all rights reserved, unless otherwise indicated.

\title{
Introduction: Within and beyond error
}

PLEASE CITE THE PUBLISHED VERSION

https://www.bloomsbury.com/au/design-ecology-politics-9781472588609/

\section{PUBLISHER}

Bloomsbury

VERSION

AM (Accepted Manuscript)

PUBLISHER STATEMENT

This paper was accepted for publication by Bloomsbury and the definitive published version is available at https://www.bloomsbury.com/au/design-ecology-politics-9781472588609/

\section{LICENCE}

CC BY-NC-ND 4.0

\section{REPOSITORY RECORD}

Boehnert, Joanna. 2019. "Introduction: Within and Beyond Error". figshare. https://hdl.handle.net/2134/35733. 


\section{Design / Ecology / Politics}

Toward the Ecocene 


\section{Design, Ecology, Politics}

\section{Toward the Ecocene}

$72,885 \mathrm{w}$

\section{Table of Contents Summary}

Introduction: Within and Beyond Error

Part One - Design

1. Design Theory 101

2. Design as Symbolic Violence

3. Design vs. The Design Industry

Part Two - Ecology

4. Ecological Theory 101

5. Epistemological Error

6. Ecological Literacy

7. Ecoliterate Design

8. Ecological Movements

9. Ecological Perception 1: Theory

10. Ecological Perception 2: Practice

11. Ecological Identity

Part Three - Politics

12. Social Marketing

13. The Green Economy

14. The TechnoFix

15. Data Visualisation

Conclusion: Towards the Ecocene

Dr. Joanna Boehnert

j.boehnert@westminster.ac.uk 
Table of Contents Iong version

Preface

Introduction: Within and Beyond Error

An Overview of Earth System Sciences and Interpretations

The Anthropocene

The Capitalocene

The Ecocene

Part One: Design

1. Design Theory 101

Design as the Mediation of Social Relations

The Political Economy of Design: Design as Emergent Order

The Role of Design in Capitalism

Socially Responsive Design Approaches and Strategies

Design for Service

Transformative Design

Design 4.0

Design for Social Innovation

Speculative Design

Re-directed Practice

Transition Design

Design Activism

2. Design as Symbolic Violence

Ecocidal Logic of Anti-Environmentalism: Ecoism

Social Theory of Power

Design as Symbolic Violence

Resisting Symbolic Violence by Design

A Theory of Change: CounterPower

3. Design vs. The Design Industry

Design $\neq$ The Design Industry

The Myth of the 'Free' Market

Distortions of Knowledge and Reason

Environmental Communication as a Crisis Discipline

Socially Responsive Design in Context

Part Two - Ecology

4. Ecological Theory 101

The Problematic Emergence of Ecological Thought

Ultra-Modernism

The Structure of Scientific Revolutions

Post-Normal Science

The Crisis of Reason

Backgrounding

Remoteness

Instrumentalization

Disengagement

Quantitative reasoning

Ecological Rationality

5. Epistemology Error

Alternative Epistemologies

Feminist Challenges + Contributions

Epistemic Selectivities, Privilege and Blindness

Indigenous Epistemologies and Epistemologies of Colour

Colonising and Decolonising Epistemologies

Traditional Ecological Knowledge

Indigeneous Epistemologies of Vitality and Kinship

Ecological Epistemologies and Ontologies

Ecological Ethics

Confronting Error

6. Ecological Literacy

Ecological Literacy vs. Sustainability

Ecological Learning Theory: Levels and Domains of Learning and Communication

Typologies of Ecological Literacy

Mode One - Experiential Ecological Literacy

Mode Two - Critical Ecological Literacy

Ecopedagogy

Systems Thinking

Ecological Literacy in Design Education

7. Ecoliterate Design

Ecological Principles for Design

Networks + Resilience

Cycles + A Circular Economy

Flows + Energy Literacy

Energy Return On Investment (EROI)

The rebound effect

Embodied energy 
Development + Emergence

Nested Systems + Systems Oriented Design

Dynamic Balance + Ecological Footprint

Ecological Principles in Design

8. Ecological Movements

Movements as Micro-Experiments

Environmental Justice

Deep ecology

Permaculture + The Transition Movements

Anarchism + Social ecology

Eco-Marxism, Eco-Socialism + Communism

Agroecology and Food Sovereignty

Indigenuity

Ecofeminism

Another World is Possible

9. Ecological Perception 1-Theory - Visual Intelligence

History of Modes of Communication

Visual Intelligence

Design Intelligence

Visual Language

Relational or Ecological Perception

Visual Metaphor

Critical Visual Literacy

10. Ecological Perception 2 - Practice - Seeing Systems

Systems Oriented Design

Addressing Epistemological Error by Design

Context

Geographic Maps

Knowledge Maps

Causality

Connections

Comparisons

Qualitative Complexity and the Aesthetic Experience

11. Ecological Identity

Activating Materialist Values and Narcissists Identities

Cultural Identity Trumps Other Factors

Strategies of Denial

Cognitive Dissonance

Ecopsychology: The Ecological + the Psychological

Neologisms for Psychoterratic States

Mental Health, Sanity and Addition

Confronting Disturbing Information

Part Three - Politics

12. Social Marketing

Social Marketing is a Distinct Type of Communication

The Case of Hopenhagen

Don't corporations also want to 'save the world'?

Lessons for Environmental Communication and Campaigns

Enable democracy and debate

Resist de-politisation encourage discursive plurality

Challenge greenwashing and misinformation

Good Intentions are Not Enough

13. The Green Economy

Natural capital and ecosystem services as feedback metaphors

Economic approaches to the environment

Problems with the natural capital approach

Philosophical problems: policy based on error

Methodological problems: Philosophy

Political problems: The Neoliberalisation of Environmental Policy

14. The TechnoFix

Environmental Skepticism and anti-environmentalism

Growing Inequalities: An Economy for the Few

Post-Environmentalists and Ecomodernists

Apolitical Design: Default to the Unsustainable

The Circular Economy: Within and Beyond Industria

3- D Printing: Beyond Pointless Plastic Products?

The Luddites and Commonality

Beyond Technocracy and Ecomodernism

15. Data / Knowledge Visualisation

Data Visualisation Does Political Things

The Limits of Quantitative Displays

The Dangers of Digital Positivism

Obscuring Datawash, Missing Dark Data

Enabling Knowledge Visualisation

Controversy Mapping

Discourse Mapping 
Critical Information Design Conclusion: Towards the Ecocene

Crisis as Catalyst 


\section{Introduction: Within and Beyond Error}

Whether or not we are interested in the environment or identify with the concept of being 'an environmentalist' each of us is entirely dependent on the air we breathe, the food we eat and the environment we inhabit for life. Despite this basic fact, statements about our connections with nature are often interpreted as platitudinous and widely dismissed. We have inherited a highly reductive intellectual tradition and anti-ecological worldview in profound denial of our fundamental interdependence with nature. We are embedded within non-human nature ${ }^{1}$ and dependent on ecological systems for life but our belief systems do not reflect this basic relationship.

Consequently, the world we have designed is deeply unsustainable.

Fragmentary thinking is an obstacle to sustainability. Reductive attitudes towards knowledge cannot address problems associated with complex ecological systems - or social and economic problems for that matter. In response to this dilemma, ecological literacy provides an integrated foundation for the understanding of environmental problems and potential solutions. Unfortunately, ecological literacy has largely failed to spread across disciplinary boundaries in over two decades since the concept was first conceived and it remains marginal in education, policy and practice. All too often it is absent in places where it is desperately needed - such as the disciplines responsible for the design of sustainable futures. In this book I focus on what ecological literacy means for communication design, although many ideas will be relevant for other design disciplines and of interest to anyone concerned with designing sustainable ways of living.

Design serves a social and political function that is not always acknowledged within the design industry. While there are prominent movements in design working towards socially responsive practice, these efforts are hampered by the manner in which power relations are reproduced by design and the lack of analysis of these dynamics. Design is a practice that functions to mediate social relations. Typically it reproduces the values and priorities of those who determine which design problems are to be addressed. The interests of powerful groups are manifested in design.

Communication design is strategically placed to be pivotal in the transformation of unsustainable ways of living. John Berger famously said, "seeing comes before words" (2008 [1972], 7). Seeing is a way new ideas emerge. Design can facilitate new ways of seeing. In particular, communication design has unique properties that can nurture new perceptual and cognitive capacities supporting relational or ecological perception and ways of knowing. Communication designers are visualisers: they can construct future scenarios with imagery before it takes form. Designers are information mediators: they can organize information and help make it meaningful. Designers are also experts in subjectivity and regularly make us want to do things in new ways. Since communication is key to mobilising responses at moments of contingency, communication designers have a significant role to play in responding to the current environmental crisis.

This is a book about design and communication (and especially communication design) in the context of converging ecological and social crises. On one level it is a book about how design influences and communicates; how it encourages us to feel how we feel; how it helps us know who we are and who we might become. It is also a book about how ideas, social relations and political structures influence how we treat our environment: what use we make of it and what care we take of it. Design negotiates the intimately intertwined space between self, society and the environment. What future we have (or don't have) will depend in many ways on what design concepts, strategies and methods we choose. In this book, I will advocate for ecoliterate design.

\footnotetext{
${ }^{1}$ The term 'non-human nature' accentuates the fact that humans are also part of nature.
} 
This book is organized in three parts:

Part One: Design introduces the role of design in society. It examines the ways in which design functions to construct and reproduce social relations. It reflects on the potential of design to be a form of symbolic violence. It considers the tensions between design as a practice for social and ecological good and the priorities embedded in the design industry.

Part Two: Ecology explores the philosophical foundations of ecological thought, its history and exactly what it means to be ecologically literate. It describes how ecological theory informs the practice of design. It introduces ecological principles for design and the concepts of ecological perception and ecological identity. This is the largest part of the book.

Part Three: Politics examines how the interests of powerful groups are manifested in design and how design can obscure these interests. It deconstructs the narrative of 'doing good' in design by examining the effectiveness of various initiatives. It reviews how social marketing, the green economy, technofixes and information visualization all do political things.

Environmental problems are situated at the intersection of these three areas. The three spheres are inspired by Felix Guattari's The Three Ecologies (published in French in 1989 and translated to English in 2000) and Gregory Bateson's Steps to an Ecology of Mind (1972). Guattari, following Bateson, proposes that mental ecology, social ecology, and environmental ecology are three realms that cannot be disconnected. In theory and practice we must work with the three ecologies (human subjectivity, social relations and the environment) simultaneously. For Guattari it is our failure to work with these realms (the mental, the social and the environmental) at once that creates contradictions and stunts efforts to address environmental problems. In The Three Ecologies he explains:

So, wherever we turn, there is the same nagging paradox: on the one hand the continuous development of new techno-scientific means to potentially resolve the dominant ecological issues and reinstate socially useful activities on the surface of the planet, and, on the other, the inability of organized social forces and constituted subjective formations to take hold of these resources in order to make them work $(2000,22)$.

In response to this dilemma, he calls for a theory of ecosophy, an "ethico-political articulation" (Ibid, 19) that will consider the dynamics between the three ecologies. A new praxis to "ward off, by every means possible, the entropic rise of a dominant subjectivity" (Ibid, 45). This work will be done by "literally reconstructing the modalities of 'group-being'... through 'communicational' interventions" for the modification and reinvention of the ways in which we live by "the motor of subjectivity" (Ibid, 24). Keeping in mind that: "There is at least a risk that there will be no more human history unless humanity undertakes a radical reconsideration of itself" (Ibid, 45), this work is necessarily hugely ambitious: "In its final account, the ecosophical problematic is the production of human existence itself in new historical contexts" (Ibid, 24). The emergence of ecological sensibilities is a basis for transformative change.

Design is a practice well placed to respond to this call. Bateson first described how the ecological struggle is in the domain of ideas (1972, 495-505; Pindar \& Sutton 2000, 11). Guattari called on all cultural practices "in a position to intervene in individual and collective psychical proceedings" $(2000,27)$ to participate in this ethico-aesthetic project to nurture a new ecological subjectivity. This book moves the theory developed by Bateson and Guattari (also Plumwood, Orr, Capra, Sewall, and others) closer to practice. As a theoretical foundation for ecologically informed design the book explores the politics of why current design practice is stuck in the reproduction of unsustainability. In bridging social theory with ecological theory, the book addresses some historical suspicions between these two fields. The tensions between these two modes need to be encountered and conjoined. As we construct new ways of relating with each other and the ecological space we inhabit, within an order that works against just, socially equitable sustainability, we must live with contradictions embedded in the political system as we attempt to dismantle and transform structures and practices to enable viable, sustainable futures. 
Figure 1. The Three Ecologies A. EcoLabs, 2017.

Figure 2. The Three Ecologies (B, C \& D). EcoLabs, 2017.

The three ecologies are reinterpreted in this book (design, ecology, politics). The ordering in the title is not true to type in an ontological sense - but pragmatic: it reflects the order in which I introduce the theory of design, ecology and politics. Designers have expertise in influencing subjectivities. Design is a field that mediates the subjective realm (the mental ecology). Politics describes the ways in which the social realm is organized (the social ecology). Ecological theory considers human relations to the environment (the environmental ecology). In this book, I attempt to bring these three spheres together. This assembly of three ecologies is both a meeting of three domains (the environmental, the social and the mental) and a recognition that these are orders embedded in each other and need to be theorized simultaneously. Inclusive theory is a basis of good design.

This book bridges different traditions. Social theory reveals the social function of design including the ways ideas and ideologies are reproduced in the communication and the objects designers make. Ecological theory describes human relationships with the environment, including the ways in which design contributes to and reproduces unsustainable conditions. Political theory describes how particular constituencies control what is designed and how these power dynamics are concealed by designers (who are often unaware of the ideological work they perform). Located at the intersection of these fields, the book explores how designers participate in the construction of future realities by creating new ways of doing things. Revealing these dynamics creates new possibilities for transformative practice.

By linking social theory and ecological theory to design theory and practice, this work critiques the ways that the design industry - and even many sustainability discourses within the design industry, perpetuates current unsustainable development regimes. When design does engage with issues of sustainability, this engagement typically remains shallow due to a narrow basis of analysis in design theory and education. The situation is made more severe by design cultures that claim to have no politics. The supposedly 'neutral' designer is typically the most unaware of their own ideological assumptions and allegiances to power, normative values and the status quo. The political system in the UK (also North America and Europe) is a political system that is built with and for capitalist economic production with its neoliberal modes of governance. This system impacts how we live our lives and what is happening to the climate. Throughout this book I review what neoliberalism means for the environment and design.

Due to the scale of current challenges, new ecologically informed technologies and design practices (such as biomimicry, circular economy, renewable energy, lifecycle analysis, etc.) must be incorporated into a larger project of political change. The insights from ecological theory can be applied to the political model itself. Design must be informed by both ecological literacy and social theory to help designers critically assess and navigate pathways to sustainability. (I provide the analytic tools for the more critical account of sustainability throughout this book). Since sustainable futures depend on not only a technological innovation but also social and political change, designers must be aware of historical circumstances that have created unsustainable ways of living and the mechanisms of social change. Design education must broaden the scope and the depth of its analysis to attend to the complexity of contemporary problems. With these insights, design can be a transformative practice.

The design industry plays an important role in the creation of consumer desire - and of neoliberal sensibilities. While encouraging particular ways of thinking, design is also often involved in concealing the impacts of consumer capitalism and in obfuscating power relations. Situated at the hub of industrial production processes designers all too often have a cynical relationship to both consumerism and capitalism - as if there is no alternative. The neoliberal political project aims to abolish alternatives. Actually, there are plenty of options once we recognise the ideological work that is being done that destroys the visibility of other possibilities. Even noticing the ideological barriers to sustainability informs 
strategies of renewal. I will start with a hard look at the context in which we are acting.

\section{An Overview of Earth System Sciences and Interpretations}

Planetary Boundaries enable the relative stability of Earth Systems (ES) and create conditions amenable for civilization. The Planetary Boundary framework defines a "safe operating space" for global societal development (see figure 3 and Chapter 7 p.x). There are now four Earth Systems that have transgressed safe limits (climate change, biosphere integrity, biogeochemical flows, and land-system change). Two of these (climate change and biosphere integrity) have the potential to drive the Earth into a new state - and not necessarily one that provides the conditions necessary for civilization. Biosphere integrity refers to pressures associated with biodiversity loss. The biosphere "regulates material and energy flows in the ES and increases its resilience to abrupt and gradual change" (Steffen et al. 2015, 736). Since all living things rely on their environment, biodiversity loss is impacted by each of the other Earth Systems. Current species extinction is now happening at a faster rate than any time since the last mass extinction event (65 million years ago). Humankind has triggered a Sixth Extinction (Kolbert 2014). Amphibians, the most endangered class of animal, are becoming extinct at 45,000 times the normal rate (Ibid, 17). While climate change tends to get more attention as the implications of destabilizing the Earth's climate system are extraordinarily perilous, all of the Earth Systems need to be considered concurrently to understand the scope of environmental harms and risks to humanity. Biosphere integrity is an alienating term for something magnificent as the animals we share the Earth with, but the scientific term reminds us that other species are often essential actors in local ecosystems that enable the regenerative processes on which humans depend.

Figure 3: Planetary Boundaries, detail of An Audit of Development. EcoLabs + Tzortzis Rallis, Lazaros Kakoulidis, 2013.

The risks associated with transgressing boundaries are severe: "Anthropogenic pressures on the Earth System have reached a scale where abrupt global environmental change can no longer be excluded" (Rockstrom et al. 2009, 1). Climate change is already causing major disruptions in Earth Systems. Warming of the atmosphere and ocean system is unequivocal and associated impacts are occurring at rates unprecedented in the historical record. Climate change presents severe risks and these impacts will become increasingly expensive, difficult and even impossible to mitigate if action is not taken to dramatically reduce greenhouse gas emissions. If business-as-usual $\mathrm{CO} 2$ emissions continue, between $21 \%$ and $52 \%$ of all species will be committed to extinction within the century (Hansen 2011). Tipping points in the Earth System can make change irreversible; "recent greenhouse gas (GHG) emissions place the Earth perilously close to dramatic climate change that could run out of our control" (Hansen 2007, 1). Despite these dangers, humanity's global carbon footprint has increased by 11-fold since 1961 (WWF $2010,8)$ and continues to rise at rates higher than ever - global emission shot up by $5.9 \%$ in 2010 , the largest absolute increase ever (Klein 2014, 18 quoting Peters et al, 2011). International negotiations have not succeeded: in 2013 carbon dioxide levels were 62\% higher than in 1990 when the Intergovernmental Panel on Climate Change (IPCC) issued its first report and negotiations started (Klein 2014, 11). The 2015 UNFCCC COP21 'Paris Agreement' was presented as a success - but for the climate justice movement it was a dramatic public relations exercise in business-as-usual.

Industrial processes are a dramatically impacting the Earth. Humankind has not yet learned how to use technology on scale in ecologically benign ways. Over the past forty years the Living Planet Index (an indicator of the state of biodiversity) has fallen by 52\% (WWF 2014, 12). In "less than two human generations, population sizes of vertebrate species have dropped by half" (WWF 2014, 4). At a global level, the yearly ecological footprint takes 1.5 years of regenerative capacity or biocapacity to replace (WWF $2014,9)$. Thus biocapacity continues to shrink while consumption rates continue to grow. Even the most basic analysis indicates the danger of this situation. Vastly disproportionate responsibility for global 
ecological problems lies with the rich: "the world's richest 500 million people (roughly 7 percent of the world's population) are currently responsible for 50 percent of the world's carbon dioxide emissions" (Assadourian 2010, 6). The first causalities of degraded natural systems are the poor. Environmental problems are also social problems and need to be approached with environmental justice in mind. A whole system's audit of the current mode of development would reveal deep flaws with the current economic model (figure 4).

Figure 4: An Audit of Development. EcoLabs, Tzortzis Rallis, Lazaros Kakoulidis, 2013.

The vital signs of the planet are included here as they are the basic background knowledge necessary for responsible design. Regrettably, in many places there remains a complete disconnect between the environmental sciences and design - between these environmental circumstances and the practices advocated by design education and the design industry. It should be evident that design that is not sustainable is deeply unethical. The Millennium Ecosystem Assessment warns that: "human activity is putting such strain on the natural functions of Earth that the ability of the planet's ecosystems to sustain future generations can no longer be taken for granted" (Assadourian 2010,4). While many of us see nonhuman nature as having value outside of its worth for humankind, even if we have no regard for nature for its own sake, the de-stablisation of global ecological systems creates grave risks for humanity. Earth System change threatens to make all other long-term goals obsolete. The capacity of the ecological system to continue to provide favorable conditions for civilization is no longer assured. In the long-term for everyone and immediate present for those in communities on the frontline of climate impacts and other environmental harms, everything depends on the ecological context.

\section{The Anthropocene}

Due to the dramatic changes that humankind is inflicting on Earth Systems, scientists warn that we are now exiting the relatively stable Holocene epoch in which civilization developed. We are entering a new geological epoch, that of the Anthropocene, wherein humankind is responsible for altering the functioning of the Earth System (Crutzen \& Stoermer 2000; Steffen, Crutzen \& McNweill 2007; Zalasiewicz et al. 2015). This power over nature has not been accompanied with the foresight to use technological capacities wisely. In Science, Will Steffen et al wrote:

The relatively stable, 11,700-year-long Holocene epoch is the only state of the ES [Earth System] that we know for certain can support contemporary human societies. There is increasing evidence that human activities are affecting ES functioning to a degree that threatens the resilience of the ES-its ability to persist in a Holocenelike state in the face of increasing human pressures and shocks (13 Feb 2015, 737).

There is debate in the scientific community on the starting date of the Anthropocene. Several dates have been proposed: the collision of the Old and New Worlds circa 1610 (Lewis \& Maslin 2015); industrialization (1800-present) (Steffen, Crutzen \& McNweill 2007); the "Great Acceleration" following WWII (Zalasiewicz et al. 2015); the nuclear weapons detonation 1945 - 1961; and with persistent industrial chemical pollution (1950s - present). A potential date is that of the world's first nuclear bomb explosion, on July $16^{\text {th }} 1945$. Thereafter "additional bombs were detonated at the average rate of one every 9.6 days until 1988 with attendant worldwide fallout easily identifiable in the chemostratigraphic record" (Zalasiewicz et al. 2015, 1). Nobel Prize winning atmospheric chemist Paul Crutzen, climate scientist Will Steffen and environmental historian John McNeil have proposed two distinct stages in the Anthropocene: the Industrial Era (from 1800 to 1945) and the Great Acceleration (from 1945 to the present) (Steffen et al., 2007). The Great Acceleration is evident in the charts in figure 5 where Earth System Trends all reveal dramatic changes mid 20 ${ }^{\text {th }}$ Century. Simon Lewis and Mark Maslin's Science paper (2015) suggests that the death of over 50 million indigenous residents of the Americas in the first century after European contact constitutes the most significant marker of the new epoch. A proposal to formalize the 'Anthropocene' is under development. Whatever date is chosen, the Anthropocene's 'literal meaning - the 'age of humans' - is either shocking or hugely flattering, depending on one's perspective" 
(Castree 2014, 235). But not all perspectives are equally well informed. Those who have the most knowledge of Earth System science are concerned and often alarmed.

Figure 5. Earth System Trends. The Trajectory of the Anthropocene: The Great Acceleration. Steffen et al. 2015.

\section{The Capitalocene}

The concept of the Anthropocene draws attention to severe environmental problems - but it also does other things. Jason W. Moore asks: "Does the Anthropocene argument obscure more than it illuminates?" $(2014,4)$. The idea has been critiqued as uncritically importing Western rationality, imperialism and anthropocentrism and thereby narrowing humankind's options for developing sustainable alternatives (Moore 2014, 2015; Latour 2014; Haraway 2014, 2015). Specific activities are destabilising climate systems and other planetary boundaries. The Capitalocene is a concept that asserts: "the logic of capital drives disruption of Earth System. Not humans in general" (Solon, 2014). Bruno Latour claims that

The "anthropos" of the Anthropocene is not exactly any body, it is made of highly localised networks of some individual bodies whose responsibility is staggering...this dispersion of the "anthropos" into specific historical and local networks, actually gives a lot of weight to the other candidate for naming the same period of geohistory, that of "capitalocene", a swift way to ascribe this responsibility to whom and to where it belongs $(2014,139)$. Not everyone shares responsibility for ecologically destructive modes of development. Power and responsibility is concentrated on those who have the ability to influence industrial development and system structures. Dana Luciano notes that destruction of Earth Systems "was not brought about by all members of the species it names" (2015, para. 16). The contradiction that is embedded in the name of the new epoch "is precisely the problem it is now up to us to solve" (Ibid). Distinguishing the specific systemic processes that drive ecological crises is key to identifying problems and constructing effective responses. The notion that all of us are responsible for the ecological crisis bolsters a particular narrative and serves the interests of those who would like to maintain business-as-usual. The name of the new epoch establishes a powerful metaphor and an associated framework that will help or hinder the struggle to mainstream sustainable design. As an alternative, the Capitalocene proposal highlights the role of capital accumulation in creating ecological crisis conditions:

...our economic system and our planetary system are now at war. Or, more accurately, our economy is at war with many forms of life on earth, including human life. What the climate needs to avoid collapse is a contraction in humanity's use of resources; what our economic model demands to avoid collapse is unfettered expansion. Only one of these sets of rules can be changed, and its not the laws of nature (Klein 2014, 21).

There is a certain model of development driving dramatic Earth System change. Humans in general have other options beyond the ones we have currently constructed. For this reason it is important to be specific about what type of development we Anthropos of the Anthropocene pursue.

\section{The Ecocene}

Beyond the hubris of the Anthropocene and the critique of the Capitalocene, new ways of understanding and organizing social and ecological relations are emergent. Critiquing the ideas, politics and technologies that have contributed to ecological crisis is only a starting point for the work to be done creating ecologically viable ways of living. Design theorist Rachel Armstrong coined the concept of an 'Ecocene'. The Ecocene shifts focus from the problems to the solutions: "There is no advantage to us to bring the Anthropocene into the future...The mythos of the Anthropocene does not help us... we must re-imagine our world and enable the Ecocene" (Armstrong 2015). The challenges today are hyper-complex but we must bring "the great dithering" to an end and catalyze a transition (Ibid). For Armstrong, now an exciting time to be a designer. The Ecocene has yet to be designed. Its emergence depends on a new understanding of human-nature relations and new types of development and design that emerge from this perspective. New ecologically informed ways of thinking and living must be generated. The transformative Ecocene describes a curative catalyst for cultural change necessary to survive the Anthropocene. The emergence of the Ecocene depends entirely on what we do now. 
This brief overview cannot do justice to either the scope of environmental problems or the difficulty in protecting ecosystems while also committing to social and environment justice within the current economic paradigm. The environment is the basis for prosperity and a foundation for social justice. Addressing its problems is a basic imperative. We require strong moral sanctions against life destroying industrial development. Until these can be created, as long as we live in a society with capitalism and a centralized state, we need robust mechanisms in the public sector to monitor, regulate and transform industry along with strong laws against ecocide. This should not be seen as end goals but rather a means of coping with the current problems while we design ways of living within and beyond the error embedded in this political system so replete with contradictions. Design is a practice that can help make this happen. 